\title{
Effect of Process and Formulation Variables on the Structural and Physical Properties in Cream Cheese using GDL Acidulant
}

\author{
Jiuk Kim ${ }^{1} \cdot$ Philip Watkinson $^{2} \cdot$ Mita Lad $^{3} \cdot$ Lara Matia-Merino $^{1} \cdot$ Jeremy R. Smith ${ }^{1} \cdot$ Matt Golding ${ }^{1}$ (I)
}

Received: 26 August 2021 / Accepted: 22 January 2022 / Published online: 14 February 2022

(c) The Author(s) 2022

\begin{abstract}
We report on the properties of analogue cream cheeses prepared using glucono delta-lactone (GDL) acidulant, notably the impact of particular processing and formulation variables, (homogenisation pressure, coagulation $\mathrm{pH}$ and temperature, and stabiliser level) on cream cheese physical, material and microstructural properties. Protein-protein and protein-fat interactions were seen to be the primary structural contributors to the physical properties of cream cheese. Cream cheese microstructure and its properties demonstrated well-defined correlations to specific and controllable processing elements within the manufacturing process, showing significance in interactions between parameters in multivariable linear regression analysis $(P<0.05)$. Summarising the effect of processing variables on key cheese properties, we observed that a progressive reduction in fat particle size of cheese milk arising from increasing homogenisation pressures was seen to increase the total surface area of fat that could be incorporated into the curd during coagulation. The greater extent of fat-fat and fat-proteins interactions during coagulation provided a reinforcing effect on the microstructure of the final cream cheese, with a corresponding increase in compressive fracture stress, shear storage modulus $\left(G^{\prime}\right)$ and shear loss modulus $\left(G^{\prime \prime}\right)$. In terms of other processing variables, cream cheese firmness was also observed to progressively increase through lowering of coagulation $\mathrm{pH}$ from 5.13 to 4.33 . Increasing coagulation temperature from $58^{\circ} \mathrm{C}$ to $78^{\circ} \mathrm{C}$ similarly caused an increase in cheese firmness. Finally, increasing the levels of added stabiliser were shown to correlate with increasing cheese firmness. Similar correlations could be observed in relation to physical properties, notably forced expressible serum separation. This model cream cheese preparation method has provided a useful model system for relating food structure to material and functional properties. In addition, it has the advantage of being able to rapidly screen many formulation and process variables because it is faster than the traditional cheesemaking. This study showed that the adjustment of process and formulation variables, either in isolation or in combination, in the manufacture of cream cheese can significantly influence the final material and textural properties of the product, thereby enabling controllable functional attributes capable of meeting different customer needs.
\end{abstract}

Keywords Cream cheese $\cdot$ Microstructure $\cdot$ Rheology $\cdot$ Process and formulation variables $\cdot$ Glucono delta-lactone

\section{Abbreviations}

GDL Glucono delta-lactone

CSLM Confocal laser scanning microscopy

SAOR Small amplitude oscillatory rheology
$G^{\prime} \quad$ Shear storage modulus

$G^{\prime \prime} \quad$ Shear loss modulus

$\tan \delta \quad$ Shear loss tangent
Matt Golding

M.Golding@massey.ac.nz

Jiuk Kim

J.Kim5@massey.ac.nz

Philip Watkinson

Philip.Watkinson@fonterra.com

Mita Lad

Mita.Lad@nottingham.ac.uk

Lara Matia-Merino

L.Matia-Merino@massey.ac.nz
Jeremy R. Smith

J.R.Smith@massey.ac.nz

1 School of Food and Advanced Technology, Massey University, Palmerston North 4442, New Zealand

2 Fonterra Research and Development Centre, Fonterra Co-Operative Group, Palmerston North 4442, New Zealand

3 Research and Innovation, University of Nottingham, Nottingham NG8 1DGH, UK 


\section{Introduction}

Cream cheese is classified as an unripened soft cheese with a slight lactic acid and diacetyl flavour [1]. It has recently gained in popularity in many countries, and its production volumes have increased consistently over the past few decades. In the US, more than 70 million pounds of cream cheese and Neufchatel cheese products were produced in 2018/19, and these outputs ranked it the fifth largest cheese production [2]. Demand in Asian countries has notably also increased in recent years owing to consumer preference for its smooth texture and mild milky flavour and diversity of applications. Indeed, the range of uses for cream cheese is expanding from traditional items like cheesecake and cheese spread, to new applications such as a beverage topping ingredient. In support of demand, a multitude of innovative applications have been developed by the foodservice sector, often in response to consumer-led trends (particularly through social media channels). These applications are helping to increase the demand and popularity of cream cheese in product areas such as dips and desserts [3].

Cream cheese is produced through sequential manufacturing processes including homogenisation, pasteurisation, acidification, coagulation and whey separation $[4,5]$. To ensure sufficient whey separation, centrifugation combined with heat treatment has become an effective and practical method for continuous manufacturing and to obtain products with consistent quality and specifications. As for the classification of its composition, a minimum milkfat content in cream cheese of at least $33 \%$ by weight of the final product is required, and with no more than $55 \%$ moisture content. From a structural perspective, cream cheese is usually considered as a coagulated protein stabilised oilin-water emulsion. The coagulation occurs during the fermentation step of the manufacturing process and initially results in the creation of a percolating network. However, the subsequent shearing and heating elements of the process serve to break up this emulsion gel network, leading to a more fluid, molten material that can be pumped into containers and which in turn sets solid during cooling and storage. Accordingly, the final structure can best be described as an acid-coagulated jammed particle gel system [6]. The dynamic changes to microstructure during the manufacturing process thus impact on the rheological properties during this processing and determine the final textural characteristics of cream cheese [7-9].

Homogenisation of milk is a well-established process which reduces fat globule size through mechanical disruption of fat globules into droplets by pushing the milk through small apertures with high pressures. This process reduces the size of fat globules in raw milk from $1 \sim 10 \mu \mathrm{m}$ diameter to $0.1 \sim 0.3 \mu \mathrm{m}$ diameter depending on homogenisation pressure $[10,11]$. For cream cheese, homogenisation of the cheese milk promoted the subsequent interaction of fat globules and protein matrix with electrostatic and hydrophobic forces by enabling adsorption of milk proteins. Proteins, such as casein micelles and denatured whey proteins, interact with the surrounding protein phase and can be easily adsorbed to the interface [12]. The effects of the interaction of smaller fat globules produced by homogenisation and the protein matrix on textural properties have been demonstrated in literature. It was reported that cheese with smaller fat globule size (being $>1 \mu \mathrm{m}$ ) contributed to higher storage modulus $\left(G^{\prime}\right)$, indicating a firmer and more elastic characteristic, whereas cheese with a larger fat globule size (around $2.7 \mu \mathrm{m}$ ) showed lower $G^{\prime}$ in the rheological temperature sweep analysis [13]. Higher firmness was observed in cheese made from homogenised milk retentates compared to unhomogenised counterparts [14]. Additionally, Coutouly, Riaublanc, Axelos, and Gaucher [15] confirmed that homogenisation pressure was the most critical manufacturing process determining the rheological properties. The increasing number of smaller fat globules after homogenisation results in a larger contactable surface area surrounded by milk proteins. The aggregation and flocculation processes lead to firmer milk gels and eventually make firmer cheese texture. Homogenisation gives an increase in the interaction of fat droplets with the protein network. While homogenisation can promote firmness in natural cheese, it can also lead to less melting and less oil release [16]. For cream cheese, promoting firmness is sometimes an advantage, less melting is not generally important, and less oil release is generally not a disadvantage; therefore, homogenisation is routinely used for cream cheese milk.

There have been some studies on the effects of fat contents in commercial products and different homogenisation pressures in cheesemaking on the physical properties. In the study investigating the physical and sensory properties of US commercial cream cheese products, most full-fat cream cheeses showed greater hardness compared with low fat or fat-free cheese products [17]. Sanchez, Beauregard, Chassagne, Bimbenet, and Hardy [7] determined that the homogenisation process made the texture of cream cheese firmer, as well as increasing the storage modulus of acid gels consisting of fat globules surrounded with caseins. The effect of two stage homogenisation on the texture of cream cheese was also investigated [9]. The authors reported that higher homogenisation pressure produced higher consistency (area under force versus time using penetrometry) for acid gels because the increased fat surface area is enclosed with proteins and in turn, this may contribute to firmer texture because of more active filler particles. Other previous studies showed similar results, that higher firmness in the 
acid milk gel was observed as higher homogenisation pressure was given to the standardised milk [18, 19]. Similarly, according to Ningtyas, Bhandari, Bansal, and Prakash [20], smaller fat globule sizes were created when homogenisation pressure was increased from 25 to $100 \mathrm{MPa}$, resulting in a firmer cream cheese texture. A self-consistent outcome of combining all these past studies indicated that higher homogenisation pressure has been suggested to cause structural changes by casein-casein interactions $[14,15,21]$. However, the effect of homogenisation conditions on the properties of full fat cream cheese has not been fully investigated using GDL in the cheesemaking, though this has the added benefit of being a simpler process than using starter culture.

The aggregation of milk protein by acidification appears most pronounced when the $\mathrm{pH}$ decreases to 4.6 , the isoelectric point of the casein micelle. The acidification of milk results in considerable structural changes and has a large impact on physico-chemical properties in the manufacturing process $[19,22]$. Acidification results in the formation of protein networks through casein micelle aggregation, leading to the gelation of milk. However, different rheological and structural properties are observed depending on the acidification methods. For example, direct acidification, for example, using GDL, has resulted in different rheological and physical properties compared to those obtained when using fermentation by lactic acid bacteria [23]. It was observed that GDL-induced gels showed shorter gelation time, higher gelation $\mathrm{pH}$ and different rheological properties than starterinduced gels, due to a different $\mathrm{pH}$ with time profile and structural rearrangements. Lowering the $\mathrm{pH}$ of milk causes a decrease of the charge on the micelles and particularly the $\kappa$-casein surface, leading to instability and casein micelle aggregation forming a gel network [24]. When the milk is coagulated under a certain low $\mathrm{pH}$ conditions, the casein micelles lose stability as colloidal calcium phosphate is solubilised and the net negative charge is reduced [25].

To investigate the microstructure of aggregated protein networks, such as in cheese, confocal laser scanning microscopy (CLSM) has been used to demonstrate the assembly of casein particles and fat droplets within a coarse particulate network. In addition, the size and spatial arrangement of a fluorescently stained fat area can be analysed by means of CLSM. It provides the advantage that the different components within the structures can be observed without destroying the structure, as laser scanning is able to penetrate the sample and visualise the internal structure. This methodology has contributed to the determination of the microstructure in acid-induced gels and cream cheese [15, 20, 26]. These workers demonstrated that the microstructure of cream cheese showed different distribution according to different manufacturing conditions, such as homogenisation and $\mathrm{pH}$.
The physical properties of cream cheese have been investigated with various rheological methods. Dynamic oscillatory rheometry is a commonly used method which can offer quantitative information about cream cheese structure over a range of time and temperature, as well as the extent of deformation [27]. Gelation is the initial step for manufacturing acid gel cheese such as cream cheese, therefore, assessment of the textural and rheological properties without damage to samples is significantly important. Small amplitude oscillatory rheology (SAOR) is regarded as a method for measuring a sinusoidal strain or stress to the material during the oscillations and its response, without damage to structure. This allows assessment of how manufacturing steps influence the physical properties of intermediate and final cream cheese products $[7,8,20,28]$. Although there is an International Dairy Federation technical specification for fracture and rheological properties of cheeses by uniaxial compression that has been used for many cheeses, for example Cheddar cheese [29], this method has not been published for cream cheese to the best of our knowledge. Empirical penetrometric methods on cream cheese that give estimates of firmness and adhesiveness have used a cone probe [17].

Determining the changes of physical properties and microstructure with cream cheese made by traditional methods requires time and labour for preparing samples, due to a series of manufacturing steps. In addition, there have been few studies on the effect of various processing conditions and content of stabiliser such as Locust bean gum (LBG) on the structural and physical properties of cream cheese prepared with a simpler way, as most studies have focused on acid milk gel and cream cheese manufactured with a traditional method. In this study, GDL-induced gelation cream cheese analogues were investigated to evaluate their effectiveness as a lab scale model and draw correlations between manufacturing variables and the concomitant changes to the material properties of these model cheeses.

\section{Materials and Methods}

\section{Model Cream Cheese Preparation}

Model cream cheese samples were prepared with $10.5 \%$ of skim milk powder (SMP, Fonterra Co-operative Group Limited, NZ) and $10.3 \%$ of anhydrous milk fat (AMF, Fonterra Co-operative Group Limited, NZ), which were dispersed in heated deionised water at $55^{\circ} \mathrm{C}$ for $30 \mathrm{~min}$. The dissolved cheese milk was blended using an Ultraturrax homogeniser (IKA, T25, Germany) at 13,500 rpm for $2 \mathrm{~min}$. The cheese milk was homogenised with $1^{\text {st }}$ stage $0,60,120$, and 180 bars and $2^{\text {nd }}$ stage 50 bars, using homogeniser (APV 2000, Copenhagen, Denmark). The compositions of cheese milk treated with different 
homogenisation pressures were analysed by MilkoScan FT2 (Foss, Hillerød, Denmark). to ensure cheese milk with the targeted composition, $10.5 \%$ fat and $3.4 \%$. The equipment uses the principle of FTIR, and provides a series of milk compositions, such as protein, fat, and total solids. The homogenised milk was acidified using GDL (Sigma-Aldrich, Co., USA). The quantity of GDL was determined by a preliminary test, added at $70^{\circ} \mathrm{C}$, and placed in a container with a water-tight cover for $1 \mathrm{~h}$. Following acidification, the clotting gel was cut and cooled to $20^{\circ} \mathrm{C}$. After cooling, the clotted gel was equally divided into centrifugation bottles and centrifuged at $8,000 \mathrm{rpm}$ for $20 \mathrm{~min}$ at $20^{\circ} \mathrm{C}$. The whey was drained to collect curd and the moisture of curd was measured with a drying method using a drying oven. Whey was added back until the curd reached $53 \sim 55 \%$ moisture. Subsequent re-heating to $70^{\circ} \mathrm{C}$ was carried out with a microwave $(700 \mathrm{~W}$ for $135 \sim 165 \mathrm{~s})$. The collected curd was blended with Thermomix (Vorwerk \& Co., Germany) for $30 \mathrm{~min}$ at $75{ }^{\circ} \mathrm{C}$ and mixed at speed 3 along with $0.8 \%$ salt and $0.15 \%$ LBG (Sigma-Aldrich, Co., USA). The final product was hot filled and stored at $6^{\circ} \mathrm{C}$ before analytical tests.

Small scale cream cheese using GDL was prepared to investigate the factors affecting the physical properties. 24 cream cheese samples were prepared with 4 different final $\mathrm{pH}$ (around 4.3, 4.5, 4.7, and 5.0), 3 different LBG contents $(0 \%, 0.15 \%$, and $0.3 \%)$, and 2 different coagulation temperature conditions $\left(58^{\circ} \mathrm{C}\right.$ and $\left.78^{\circ} \mathrm{C}\right)$. To reach the different target $\mathrm{pH}$ at two different temperature conditions after $1 \mathrm{~h}$, the different amount of GDL required was determined through a preliminary test, because the reaction speed of GDL has a temperature-dependant characteristic. The milk for 24 cream cheese preparations was homogenised with $1^{\text {st }}$ stage 120 bar and $2^{\text {nd }}$ stage 50 bar as a fixed pressure. A summary of the experimental plan was shown in Fig. 1.

\section{Compositional Analysis}

The fat and protein contents of standardised milk were analysed by MilkoScan FT2. The moisture content in cream cheese was determined by drying at $135^{\circ} \mathrm{C}$ for $2 \mathrm{~h}$ (AOAC, 2005; method 930.15). The moisture content of samples was calculated as a percentage and the fat and protein in cream cheese were determined by AOAC method 933.05 using petroleum ether or ethyl ether and 920.123 using Kjeldahl method, respectively [30].

Moisturecontent $(\%)=\frac{\text { Wetweight }(g)-\operatorname{Driedweight}(g)}{\operatorname{Wetweight}(g)} \times 100$

\section{Particle Size Distribution}

The fat globule distribution of cream cheese was measured by laser diffraction by using a Mastersizer 2000 (Malvern Instruments Ltd., Worcestershire, UK), equipped with a red $\mathrm{He}-\mathrm{Ne}$ laser beam $(633 \mathrm{~nm})$ and a blue light source $(466 \mathrm{~nm})$ as previously described [31]. Cream cheese samples $(\sim 0.5 \mathrm{~g})$ were taken from each cheese sample and dissolved in $50 \mathrm{ml}$ Walstra solution overnight to disperse fully in the solution at room temperature to distinguish between flocculation and coalescence (for fat particles). Walstra solution was made with $0.375 \%(\mathrm{w} / \mathrm{v})$ disodium ethylene diamine tetra-acetate (EDTA, Sigma-Aldrich, Co., USA) and $0.125 \%(\mathrm{v} / \mathrm{v})$ polyoxyethylene sorbitan monolaurate (Tween 20, Sigma-Aldrich, Co., USA) in RO water, and then the $\mathrm{pH}$ was adjusted to 10.0 with $0.1 \mathrm{M} \mathrm{NaOH}$ (Fisher

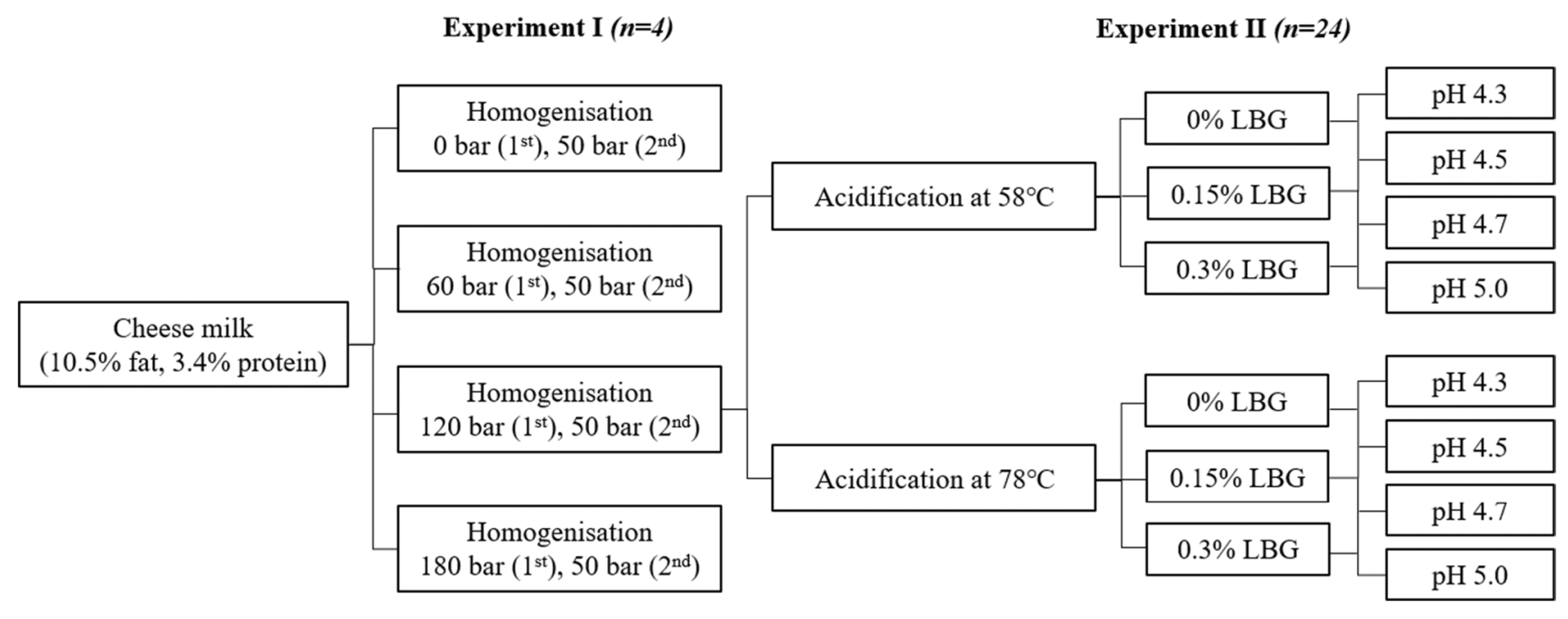

Fig. 1 General overview of the treatments for cream cheese used in the study 
Scientific, Loughborough, UK). Measurements were performed in duplicate at an obscuration value of $12 \%$. From the size distribution obtained, the volume-weighted median diameter was calculated using the Malvern software. Volume-weighted mean diameter $[\mathrm{D}(4,3)]$, the surface weighted mean diameter $[\mathrm{D}(3,2)]$, and $90 \%$ of the volume particles diameter $[\mathrm{d}(0.9)]$ were determined.

\section{Forced Serum Release}

To determine forced serum release, samples were analysed by a centrifugation method with reference to previous studies [32, 33]. Samples were cylindrically cut, $7.5 \mathrm{~mm}$ diameter and $10 \mathrm{~mm}$ height, by using a cork borer. The samples were spun using a filtered tube with $0.45 \mu \mathrm{m}$ pore size filter (Merck KGaA, Darmstadt, Germany) to avoid the mixing of released serum and the cream cheese matrix. The determination of the released serum of cream cheese made with 4 different homogenisation pressures was carried out based on a stepwise increase in $g$-force. Increasing speed was applied between $100 \mathrm{~g}$ and $12,000 \mathrm{~g}$ (9 points) at $20^{\circ} \mathrm{C}$ for $20 \mathrm{~min}$ to examine the serum release behaviour and distinguish the differences between samples. The quantity of released serum in 24 cheese samples was measured at $100 \mathrm{~g}, 500 \mathrm{~g}, 1000 \mathrm{~g}, 3000 \mathrm{~g}$, and $9000 \mathrm{~g}$ (5 points). Before each centrifugal step, each of inner and outer tube was weighed and the weighed sample was put into the inner tube. After centrifugation, the inner tube was removed and the outer tube with released serum was weighed. The quantity of released serum was measured in duplicate and calculated as a percentage of sample weight before centrifugation.

Totalreleasedserum $(\%)=\frac{\text { Releasedserumweight }(g)}{\text { Sampleweight }(g)} \times 100$

\section{Compressive Fracture and Rheological Properties}

Cylindrical samples were prepared, $19 \mathrm{~mm}$ diameter and $25 \mathrm{~mm}$ height, and tested by a TA-XT Plus Texture Analyser (Stable Micro Systems, Godalming, England) performing a lubricated double compression. The samples were cut with a cork borer, wrapped with plastic wrap and kept at $10^{\circ} \mathrm{C}$ in the refrigerator before testing at ambient laboratory temperatures. Each sample was taken just before testing from the refrigerator and after lubrication with mineral oil, experienced two successive $80 \%$ compressions by using $60 \mathrm{~mm}$ Teflon probe with a $50 \mathrm{~kg}$ load cell and compression speed $0.83 \mathrm{~mm} / \mathrm{s}$. Six replicates were taken from each sample. This test gives fracture and rheological properties in the first compression and empirical adhesion area with the tension stroke. From this data the parameters of fracture stress (firmness), fracture strain (longness), fracture area (toughness), modulus of deformability (stiffness), and adhesion area (adhesiveness) were obtained.

\section{Rheological Analysis}

Rheological properties were analysed using Anton Paar MCR 302 rheometer (Graz, Austria) according to the small amplitude oscillatory rheology method. The samples with $2 \mathrm{~mm}$ height measuring position were placed on a $25 \mathrm{~mm}$ serrated plate to avoid slippage of sample during oscillation tests [34]. Frequency sweep measurements were carried out at the linear viscoelastic region at $5{ }^{\circ} \mathrm{C}$ at 30 points between 0.1 and $10 \mathrm{~Hz}$. A temperature sweep test was conducted with the same size serrated plate, and mineral oil was added to the sample for preventing evaporation. The results were obtained by heating from 10 to $90^{\circ} \mathrm{C}$ at a rate of $4^{\circ} \mathrm{C}$ a minute, with 100 points collected during the test. The samples were measured under an angular frequency of $10 \mathrm{~s}^{-1}$ at a strain rate of $0.03 \%$. All the samples were tested in duplicate. The data of the storage, loss modulus $\left(G^{\prime}\right.$ and $\left.G^{\prime \prime}\right)$ and loss tangent $\left(\tan \delta=G^{\prime \prime} / G^{\prime}\right)$ were obtained using RheoPlus software (Anton Paar, Austria).

\section{Confocal Laser Scanning Microscopy}

The microstructure of cream cheese products was analysed using a Leica SP5 Confocal Laser Scanning Microscope (CLSM, Leica Microsystems, Wetzlar, Germany). Samples were cut using a razor blade and the protein stained with a mixture of $0.2 \%$ Fast Green and the fat stained with $0.5 \%$ Nile Red. The two staining solutions were mixed in the ratio 1:1 with polyethylene glycol. $10 \mu \mathrm{l}$ of mixed dye solution was added to the sample with a cover slip and left for $2 \mathrm{~h}$ to give a sufficient dyeing effect before examination by microscopy. An Argon laser at $488 \mathrm{~nm}$ and a Helium/Neon laser at $633 \mathrm{~nm}$ were used for excitation of the two dyes at room temperature. The samples were observed with a 63 $\times$ immersion objective, and the images were collected and viewed using Leica LAS Lite software (Leica Microsystems, Wetzlar, Germany).

\section{Statistical Analyses}

To evaluate the impact of each parameter on the physical properties of cream cheese using GDL, data was analysed by multivariable linear regression using $\mathrm{R}$ software and associations were considered significant if $P<0.05$. To assess the effects between processing variables on the physical properties in multiple regression, the interactions were subjected to two-way (if analysed) at a significance level of $P<0.05$. 


\section{Results and Discussion}

\section{Composition of Cheese Milk and Cream Cheese Preparations}

Fat and protein contents in homogenised cheese milk and cream cheese treated with 4 different homogenisation pressures $(0,60,120$, and 180 bar $)$ were found to be not significantly different. The fat and protein in cheese milk were $10.5 \%$ and $3.5 \%$ respectively, with the composition of the corresponding cream cheeses in the expected range of values meeting USDA specifications for cream cheese, with 55\% moisture and 33\% milkfat.

Compositional variance in 24 cheese samples prepared with 4 different $\mathrm{pH}, 3$ different LBG contents, and 2 coagulation temperature conditions is presented in Table 1 . The samples showed similar composition across all formulations and the measured values of each component were not

Table 1 The composition of cream cheese with different compositional and processing parameters

\begin{tabular}{|c|c|c|c|c|}
\hline $\mathrm{pH}$ & LBG $(\%)$ & Moisture (\%) & Protein $(\%)$ & Fat $(\%)$ \\
\hline \multicolumn{5}{|c|}{$58^{\circ} \mathrm{C}$ coagulation temperature } \\
\hline \multirow[t]{3}{*}{4.33} & 0 & 55.2 & 6.9 & 31.8 \\
\hline & 0.15 & 54.3 & 7.2 & 32.5 \\
\hline & 0.30 & 54.7 & 7.1 & 32.8 \\
\hline \multirow[t]{3}{*}{4.53} & 0 & 54.3 & 7.2 & 30.3 \\
\hline & 0.15 & 54.8 & 6.8 & 31.1 \\
\hline & 0.30 & 54.9 & 7.3 & 31.8 \\
\hline \multirow[t]{3}{*}{4.72} & 0 & 54.8 & 7.2 & 31.3 \\
\hline & 0.15 & 55.1 & 7.4 & 31.4 \\
\hline & 0.30 & 54.9 & 6.9 & 32.8 \\
\hline \multirow[t]{3}{*}{5.12} & 0 & 54.8 & 6.8 & 32.1 \\
\hline & 0.15 & 55.3 & 7.1 & 32.9 \\
\hline & 0.30 & 55.4 & 7.2 & 32.5 \\
\hline \multicolumn{5}{|c|}{$78^{\circ} \mathrm{C}$ coagulation temperature } \\
\hline \multirow[t]{3}{*}{4.28} & 0 & 54.8 & 7.2 & 32.4 \\
\hline & 0.15 & 53.6 & 7.5 & 33.3 \\
\hline & 0.30 & 53.1 & 7.3 & 32.6 \\
\hline \multirow[t]{3}{*}{4.52} & 0 & 54.1 & 7.8 & 31.8 \\
\hline & 0.15 & 55.2 & 7.2 & 31.5 \\
\hline & 0.30 & 53.3 & 7.6 & 31.6 \\
\hline \multirow[t]{3}{*}{4.73} & 0 & 54.8 & 7.7 & 32.6 \\
\hline & 0.15 & 54.2 & 7.6 & 31.9 \\
\hline & 0.30 & 53.9 & 7.6 & 33.0 \\
\hline \multirow[t]{3}{*}{5.08} & 0 & 53.9 & 7.4 & 32.8 \\
\hline & 0.15 & 54.3 & 7.9 & 31.7 \\
\hline & 0.30 & 54.7 & 7.8 & 33.3 \\
\hline
\end{tabular}

Values are presents as mean of duplicated measurement affected by manufacturing process variables as no significant differences were detected.

\section{Particle Size Distribution}

The effect of homogenisation pressure on the particle size distribution and modal distribution parameters [D(4,3), D $(3,2)$, and $\mathrm{d}(0.9)$ ] of cheese milk and cream cheese is shown in Table 2. It is important to reiterate that curd and cream cheese samples were treated with a dissociating solution prior to analysis which essentially causes breakup of casein micelles, aggregated casein structures and interfacially aggregated fat droplets. Thus, particle size measurements are intended to provide representation of changes to fat droplet size distribution as a consequence of the varying process steps.

Data show decreasing fat droplet size with increasing homogenisation pressure of the homogenised cheese milk. The values of $\mathrm{D}(4,3)$ and $\mathrm{d}(0.9)$ of cheese milk homogenised at 0 bar $(3.38 \mu \mathrm{m}$ and $0.82 \mu \mathrm{m})$ were larger than those ( $1.25 \mu \mathrm{m}$ and $0.45 \mu \mathrm{m})$ of cheese milk subjected to $180 \mathrm{bar}$. These results are fully expected, and in agreement with prior studies, such as presented by Rudan, Barbano, and Kindstedt [14] who found that a larger value of $\mathrm{D}(4,3)$ in unhomogenised milk was observed compared with homogenised milk for making Mozzarella cheese.

Higher homogenisation pressures not only significantly reduced the particle size of cheese milk but also produced smaller size when the cream cheese was made from that corresponding milk. For cream cheese samples, bimodal distributions were observed across all the samples (Fig. 2). With the exception of cream cheese prepared from cheese milk homogenised at 180 bar, samples showed a second distribution of larger droplets in the cream cheese as well as cheese milk. This second modal distribution represented larger particles in the range $100 \sim 1,000 \mu \mathrm{m}$, whilst the first modal distribution was in the range $10 \sim 50 \mu \mathrm{m}$, showing a

Table 2 The difference of particle size distribution in cheese milk made by different homogenisation pressures

\begin{tabular}{llll}
\hline Treatment (bar) & $\mathrm{D}(4,3)^{\mathrm{a}}$ & $\mathrm{D}(3,2)^{\mathrm{b}}$ & $\mathrm{d}(0.9)^{\mathrm{c}}$ \\
\hline $\mathrm{CM}^{\mathrm{d}}$ 0 & 3.38 & 0.82 & 7.14 \\
CM 60 & 2.24 & 0.59 & 4.48 \\
CM 120 & 1.69 & 0.48 & 3.59 \\
CM 180 & 1.25 & 0.45 & 2.68 \\
\hline
\end{tabular}

Values are presented as mean of triplicated measurement

${ }^{a}$ Volume-weighted mean diameter $(\mu m)$

${ }^{\mathrm{b}}$ Surface-weighted mean diameter $(\mu \mathrm{m})$

${ }^{\mathrm{c}} 90 \%$ of the volume particles diameter $(\mu \mathrm{m})$

${ }^{\mathrm{d}}$ Cheese milk 


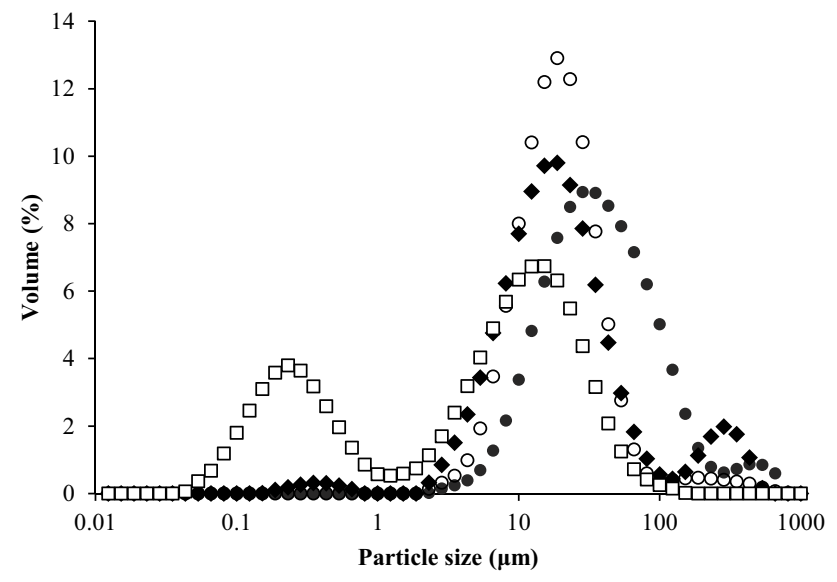

Fig. 2 Particle size distribution in cream cheese made by different homogenisation pressures; 0 bar:, 60 bar: $>, 120$ bar: $\bigcirc, 180$ bar: $\square$

decrease (mean value) particle size distribution corresponding to increasing pressure of the cheese milk.

The sample homogenised at 180 bar did not show the second modal distribution of larger droplets but showed a first peak in the size range $(0.1 \sim 1 \mu \mathrm{m})$, this being this greater peak (higher proportion of particles at this size than 120 bar homogenisation pressure). The higher surface area of fat generated by progressively increasing homogenisation pressure of the cheese milk is expected to increase interaction and binding of fat droplets into the casein protein network during coagulation. Furthermore, fat-fat droplet interactions and aggregation are cited as a mechanism for the formation of larger, coalesced fat domains (termed "free fat") represented by the upper modal distributions in particles size measurements, due to the increased propensity for film rupture of droplets in close proximity under shearing conditions. The impact of homogenisation pressure on particle size and distribution is accordingly considered a significant process lever in modulating the physical properties of the final system $[7,15,35]$.

The effect of $\mathrm{pH}, \mathrm{LBG}$ content, and coagulation temperature on the particle size distribution and modal distribution parameters $[\mathrm{D}(4,3), \mathrm{D}(3,2)$, and $\mathrm{d}(0.9)]$ of cheese milk and the final cream cheese samples were also determined and are presented in Table 3. The particle size of cream cheese subjected to higher $\mathrm{pH}$ and temperature was significantly larger than samples treated with lower $\mathrm{pH}$ and temperature [35].

Notably, all the parameters in particle size distribution showed an increasing trend of larger particle size in both temperature conditions with increasing $\mathrm{pH}$. In the multivariable linear regression analysis, lower $\mathrm{pH}$ was the most significant factor to cause the larger particles with $P<0.001$ (Table 4$)$. In the result of $\mathrm{d}(0.9)$, LBG content was partially observed as an influential factor in determining the particle size alongside $\mathrm{pH}$, however, the variables of temperature and LBG did not influence the particle size in the parameters of $\mathrm{D}(4,3)$ and $\mathrm{D}(3,2)$. This is likely due to LBG modulating the viscosity of the serum (i.e. the aqueous component not associated with casein micelle hydration), which may have a limiting effect on the physical particle size [36]. The two-way (statistical) interaction between temperature and $\mathrm{pH}$

Table 3 The difference of particle size distribution in cream cheeses made by different final pH, LBG content and coagulation temperature

\begin{tabular}{|c|c|c|c|c|c|c|c|c|c|}
\hline \multicolumn{2}{|c|}{ Treatment at $58^{\circ} \mathrm{C}$} & \multirow[t]{2}{*}{$\mathrm{D}(4,3)^{\mathrm{a}}$} & \multirow[t]{2}{*}{$\mathrm{D}(3,2)^{\mathrm{b}}$} & \multirow[t]{2}{*}{$\mathrm{d}(0.9)^{\mathrm{c}}$} & \multicolumn{2}{|c|}{ Treatment at $78^{\circ} \mathrm{C}$} & \multirow[t]{2}{*}{$\mathrm{D}(4,3)$} & \multirow[t]{2}{*}{$\mathrm{D}(3,2)$} & \multirow[t]{2}{*}{$\mathrm{d}(0.9)$} \\
\hline $\mathrm{pH}$ & LBG & & & & $\mathrm{pH}$ & LBG & & & \\
\hline \multirow[t]{3}{*}{4.33} & $0 \%$ & $21.85 \pm 0.78$ & $10.46 \pm 0.40$ & $41.82 \pm 0.81$ & 4.28 & $0 \%$ & $19.39 \pm 0.92$ & $9.76 \pm 0.64$ & $38.46 \pm 0.65$ \\
\hline & $0.15 \%$ & $23.46 \pm 1.15$ & $11.15 \pm 1.66$ & $38.69 \pm 1.57$ & & $0.15 \%$ & $22.38 \pm 0.43$ & $10.17 \pm 0.39$ & $43.16 \pm 0.78$ \\
\hline & $0.30 \%$ & $22.71 \pm 0.83$ & $12.49 \pm 1.20$ & $42.13 \pm 0.92$ & & $0.30 \%$ & $23.95 \pm 0.79$ & $10.36 \pm 0.43$ & $39.61 \pm 0.59$ \\
\hline \multirow[t]{3}{*}{4.53} & $0 \%$ & $23.93 \pm 1.22$ & $13.91 \pm 1.45$ & $43.31 \pm 0.43$ & 4.52 & $0 \%$ & $24.86 \pm 0.88$ & $12.36 \pm 0.50$ & $43.16 \pm 0.91$ \\
\hline & $0.15 \%$ & $24.63 \pm 0.99$ & $14.71 \pm 0.90$ & $48.92 \pm 0.28$ & & $0.15 \%$ & $22.19 \pm 0.36$ & $13.49 \pm 0.63$ & $45.69 \pm 1.39$ \\
\hline & $0.30 \%$ & $25.16 \pm 1.18$ & $12.94 \pm 1.32$ & $45.16 \pm 2.66$ & & $0.30 \%$ & $27.36 \pm 0.55$ & $11.67 \pm 0.36$ & $48.16 \pm 1.77$ \\
\hline \multirow[t]{3}{*}{4.72} & $0 \%$ & $27.46 \pm 0.87$ & $13.43 \pm 1.42$ & $52.36 \pm 1.56$ & 4.73 & $0 \%$ & $26.73 \pm 1.61$ & $14.36 \pm 0.33$ & $50.94 \pm 1.39$ \\
\hline & $0.15 \%$ & $29.41 \pm 1.40$ & $11.61 \pm 0.44$ & $49.31 \pm 1.35$ & & $0.15 \%$ & $30.71 \pm 0.51$ & $15.97 \pm 0.47$ & $53.39 \pm 1.22$ \\
\hline & $0.30 \%$ & $26.49 \pm 0.74$ & $14.09 \pm 0.64$ & $51.89 \pm 1.25$ & & $0.30 \%$ & $25.93 \pm 0.18$ & $13.46 \pm 0.72$ & $55.16 \pm 0.72$ \\
\hline \multirow[t]{3}{*}{5.12} & $0 \%$ & $31.16 \pm 0.32$ & $20.31 \pm 1.64$ & $55.16 \pm 0.20$ & 5.08 & $0 \%$ & $34.12 \pm 0.27$ & $19.37 \pm 0.40$ & $58.31 \pm 0.35$ \\
\hline & $0.15 \%$ & $32.76 \pm 0.91$ & $18.64 \pm 0.70$ & $58.49 \pm 1.56$ & & $0.15 \%$ & $32.69 \pm 0.41$ & $17.33 \pm 0.12$ & $62.36 \pm 0.39$ \\
\hline & $0.30 \%$ & $30.16 \pm 0.65$ & $19.34 \pm 1.21$ & $59.14 \pm 1.23$ & & $0.30 \%$ & $35.26 \pm 1.07$ & $21.39 \pm 1.07$ & $61.34 \pm 0.77$ \\
\hline
\end{tabular}

Values are presented as means \pm standard deviation of triplicated measurement

${ }^{\text {a }} \mathrm{D}(4,3)$ : volume-weighted mean diameter $(\mu m)$

${ }^{\mathrm{b}} \mathrm{D}(3,2)$ : Surface-weighted mean diameter $(\mu m)$

${ }^{c} \mathrm{~d}(0.9)$ : $90 \%$ of the volume particles diameter $(\mu \mathrm{m})$ 
Table 4 Multivariable linear regression analysis for the effects of $\mathrm{pH}$, LBG contents, and temperature as manufacturing variables on particle size distribution

\begin{tabular}{lrlc}
\hline Factor & Coefficient & Standard error & $P$-value \\
\hline PSD_D(4,3) & & & \\
Temperature (A) & 0.03 & 0.03 & 0.33 \\
pH (B) & 13.13 & 0.91 & $<0.001$ \\
LBG (C) & 3.13 & 2.19 & 0.16 \\
A x B & 0.21 & 0.08 & $<0.05$ \\
PSD_D(3,2) & & & \\
Temperature (A) & -0.01 & 0.02 & 0.55 \\
pH (B) & 10.53 & 0.79 & $<0.001$ \\
LBG (C) & 0.74 & 1.91 & 0.70 \\
PSD-d(0.9) & & & 0.11 \\
Temperature (A) & 0.06 & 0.03 & $<0.001$ \\
pH (B) & 23.24 & 1.16 & $<0.01$ \\
LBG (C) & 7.95 & 2.81 & $<0.05$ \\
A x B & 0.24 & 0.11 & \\
\hline
\end{tabular}

showed that the particle size was significantly affected for $\mathrm{D}(4,3)$ and $\mathrm{d}(0.9)$, but not for $\mathrm{D}(3,2)$, which may be indicative that these variables have an impact on the extent of free fat formation (as exemplified by the statistical significance for $\mathrm{D}[4,3])$.

\section{Forced Serum Release}

Forced serum determination, which provides an indicator of the water-holding capacity of cream cheese was evaluated. Figure 3 shows the forced serum behaviour of cream cheese at different homogenisation pressures. The line with circle dots indicates cumulative quantity removed after each step and the line with square dots shows the quantity of released serum after each step of $g$ force. Sample composition in terms of moisture, fat and protein content was not seen to notably influence serum separation. However, the relative homogenisation pressure applied to the cheese milks was seen to significantly affected the amount of released serum in cream cheese samples. Figure 3 shows that lower serum quantity was released as higher homogenisation pressures were applied to the cheese milk. The sample subjected to 180 bar showed half level of the released serum ( $13.33 \%)$ compared to 0 bar $(27.99 \%)$. At the final centrifugal step at $12,000 \mathrm{~g}$, the treatment of homogenisation pressure, 60 and 120 bar showed released serum of $22.12 \%$ and $17.25 \%$, respectively. More than half of total serum was released below $1,000 \mathrm{~g}$ centrifugal force. In the range of 100 to $1,000 \mathrm{~g}$ stepwise force, the behaviour of released serum initially showed a steep curve in all samples and then the curve gradually increased. Wolfschoon-Pombo, Dang, and Chiriboga
Fig. 3 Released serum quantity of cream cheese with different final $\mathrm{pH}, \mathrm{LBG}$ content and coagulation temperature. The line with circle dots presents the cumulative quantity after each step and the line with square dots presents the released serum quantity at each step of $g$-force. Values are presented as means of triplicates

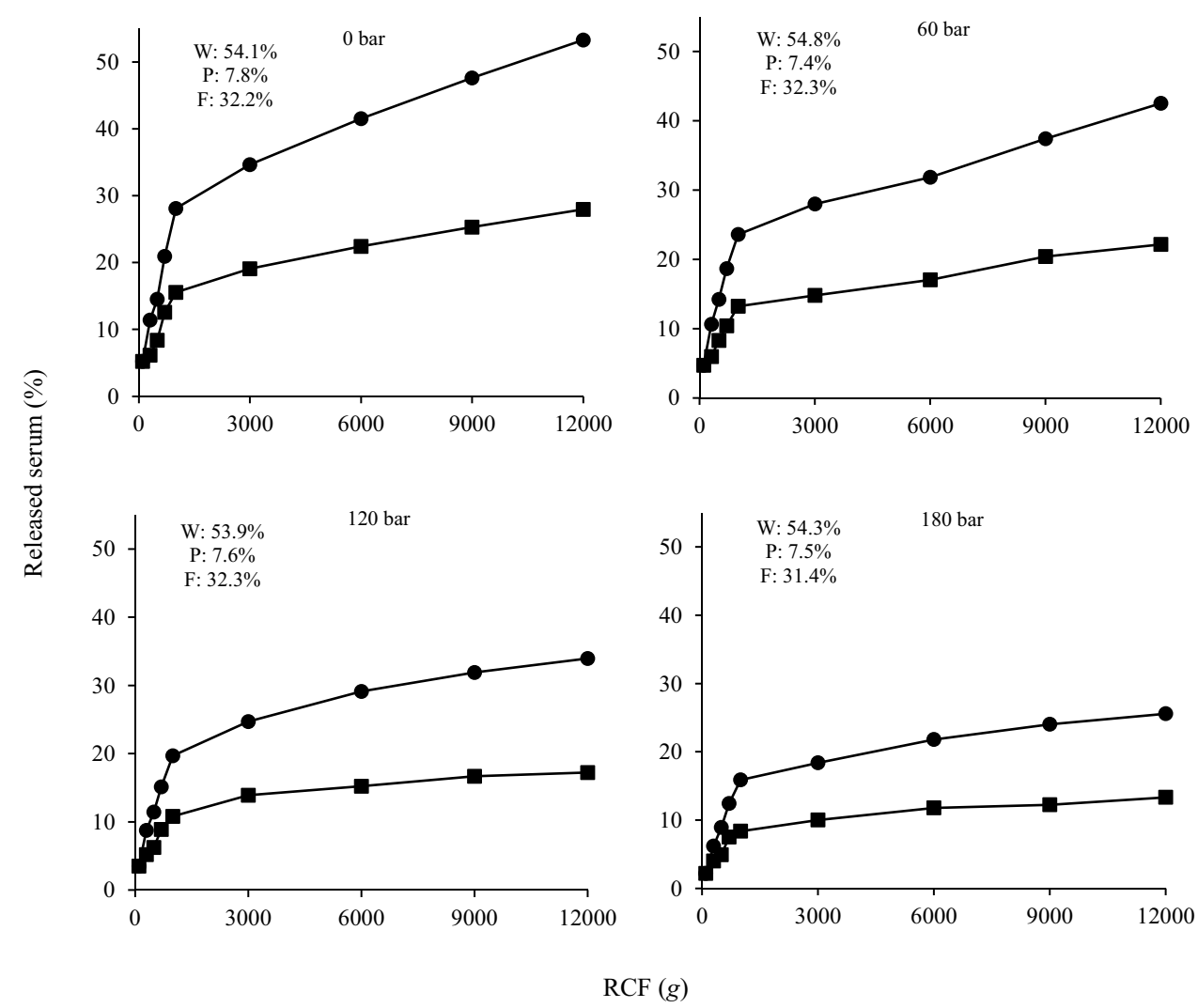


[33] discussed that the fat could interact with casein micelles forming the gel matrix and impede the syneresis from the gel network by obstructing some pores in the cheese protein matrix when it has enough fat content.

The trend of forced serum variation with $\mathrm{pH}$ and LBG content as function of the centrifugal force is shown in Fig. 4. $\mathrm{pH}$ had a direct substantial impact on expressible serum quantity at both coagulation temperatures investigated. Lower quantity of released serum was measured as cream cheese had higher $\mathrm{pH}$. This result is in agreement with a previous study which reported that higher $\mathrm{pH}$ promoted water-casein interactions, increasing water holding capacity [37]. In addition, increasing LBG content correlated with reduced expressible serum released across every centrifugal force. Multivariable linear regression analysis showed that $\mathrm{pH}$ and LBG content had a significant impact on the behaviour of forced serum release (Table 5). These results may also have implications for cheese microstructure because casein-to-water interactions can be a powerful modulator of microstructure, due to the water holding capacity of the protein. On the other hand, temperature did not influence the serum release as a single variable, and this observation suggests that any dynamic variance in water holding capacity during process may not alter the properties of the final cream cheese at post-processing. Interestingly, an interaction between temperature and LBG was shown, which suggests there is a correlation in both variables. However, there is no immediate explanation for this combined effect, noting that the heating step is conducted prior to mixing process with LBG, and thus not a combined process.
Table 5 Multivariable linear regression analysis for released serum quantity of cream cheese made from different final $\mathrm{pH}, \mathrm{LBG}$ content and coagulation temperature

\begin{tabular}{|c|c|c|c|}
\hline Factor & Coefficient & Standard error & $P$-value \\
\hline \multicolumn{4}{|c|}{ Released serum quantity } \\
\hline Temperature (A) & -0.15 & 0.02 & 0.69 \\
\hline $\mathrm{pH}(\mathrm{B})$ & -5.02 & 0.70 & $<0.001$ \\
\hline $\mathrm{LBG}(\mathrm{C})$ & -12.58 & 1.68 & $<0.001$ \\
\hline $\mathrm{A} \times \mathrm{B}$ & -0.02 & 0.06 & 0.80 \\
\hline B $\times$ C & 13.06 & 5.13 & $<0.05$ \\
\hline $\mathrm{A} \times \mathrm{C}$ & -0.38 & 0.15 & $<0.05$ \\
\hline
\end{tabular}

\section{Compressive Fracture and Rheological Properties}

The textural attributes of cream cheese made at different homogenisation pressures were monitored using uniaxial compression test. The results are presented in Table 6 . As higher homogenisation pressures were applied, higher values of modulus and fracture stress were recorded in all measured samples. Exposing cheese milk to a higher homogenisation pressure caused the reduction of fat globule size, leading to more contactable surface that more casein micelles of cream cheese can surround, thereby contributing to firmer and stiffer texture in the final product. In other words, an increase in the homogenisation pressure of the cheese milk resulted in increased firmness, toughness, stiffness, and adhesiveness in cream cheese samples. This result is noticeable because there were no significant differences in the moisture contents of cream cheese made from different homogenisation pressures.

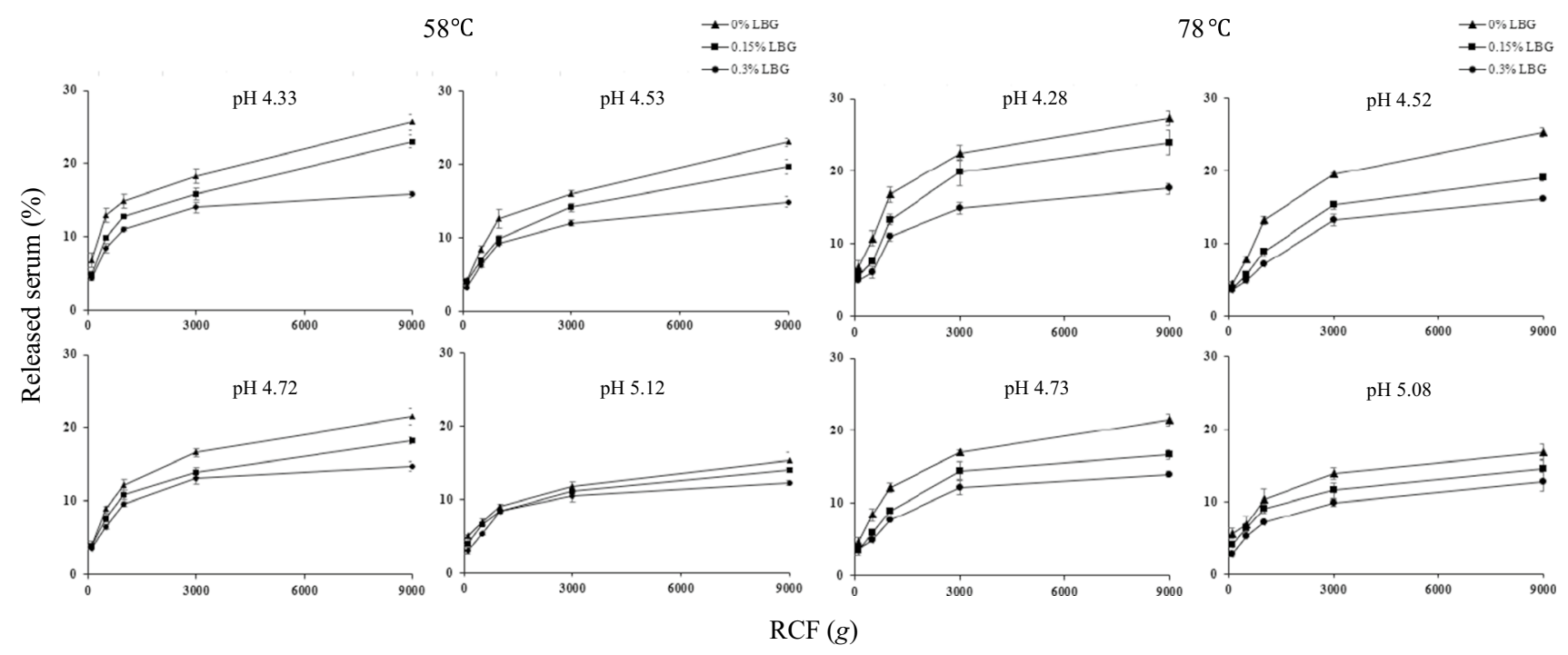

Fig. 4 Released serum quantity of cream cheese made from different final pH, LBG content and coagulation temperature. Values are presented as means and standard deviation of triplicates 
Table 6 Compression test result on cream cheese made from different homogenisation pressures

\begin{tabular}{|c|c|c|c|c|c|}
\hline \multirow[t]{2}{*}{ Treatment (bar) } & Fracture stress $(\mathrm{kPa})$ & Fracture strain (-) & Fracture area $\left(\mathrm{kJ} / \mathrm{m}^{3}\right)$ & $\begin{array}{l}\text { Modulus deform- } \\
\text { ability }(\mathrm{kPa})\end{array}$ & Adhesion area $(\mathrm{mJ})$ \\
\hline & Firmness $^{\mathrm{a}}$ & Longness $^{\mathrm{b}}$ & Toughness $^{\mathrm{c}}$ & Stiffness ${ }^{\mathrm{d}}$ & Adhesiveness $^{\mathrm{e}}$ \\
\hline $\mathrm{CC} 0$ & $9.93 \pm 0.25^{*}$ & $0.25 \pm 0.08$ & $1.16 \pm 0.15$ & $72.80 \pm 5.25$ & $6.89 \pm 1.28$ \\
\hline CC 60/50 & $10.48 \pm 0.58$ & $0.26 \pm 0.05$ & $1.47 \pm 0.19$ & $81.52 \pm 3.37$ & $7.45 \pm 1.12$ \\
\hline CC $120 / 50$ & $12.73 \pm 1.12$ & $0.39 \pm 0.15$ & $1.51 \pm 0.26$ & $85.80 \pm 6.46$ & $14.11 \pm 1.42$ \\
\hline CC 180/50 & $15.27 \pm 1.25$ & $0.29 \pm 0.09$ & $2.61 \pm 0.33$ & $96.78 \pm 3.25$ & $18.19 \pm 2.33$ \\
\hline
\end{tabular}

${ }^{\text {a }}$ Force to crack

${ }^{\mathrm{b}}$ Resistance to crumbling

${ }^{c}$ Time to chew sample before swallowing

${ }^{\mathrm{d}}$ Force to dent surface

${ }^{\mathrm{e}}$ Force that exits in the area of contact

* Values are presented as means \pm standard deviation of 6 replicates

Treatment with high homogenisation pressure gives rise to firmer and stiffer properties in cream cheese and this tendency is in line with the previous reports. Sfakianakis and Tzia [38] suggested that treatment with higher pressure on the cheese milk possibly enables the casein micelles to be adsorbed at the narrow surface of reduced fat globules and results in collision and re-aggregation of small fat globules. Another study showed that higher pressure generated more small fat globules, which increases possible cross-linking interactions between casein particles and the surface of the newly formed small fat globules, promoting more possible fat-protein and fat-fat interactions and firmer textures due to the role of particles as active fillers [12, 39].

The textural properties in cream cheese made at different $\mathrm{pH}, \mathrm{LBG}$ content, and coagulation temperature were influenced by formulation variables (Fig. 5). Firstly, the firmness and stiffness of the cream cheese were significantly influenced by $\mathrm{pH}$. As cream cheese samples had lower $\mathrm{pH}$ (by more acidulant), they showed firmer and stiffer texture as also reported earlier [40]. This is likely to be associated to a decrease of charges on casein at isoelectric $\mathrm{pH}$ and therefore a decrease of electrostatic repulsive forces-which would favour stronger protein-protein interactions increasing the
Fig. 5 Comparison of the fracture stress (firmness) and modulus deformability (stiffness) of cream cheese with different final $\mathrm{pH}$, LBG content and coagulation temperature. Bars are presented as means of 6 duplicates and error bars indicate standard deviation of the mean $58^{\circ} \mathrm{C}$

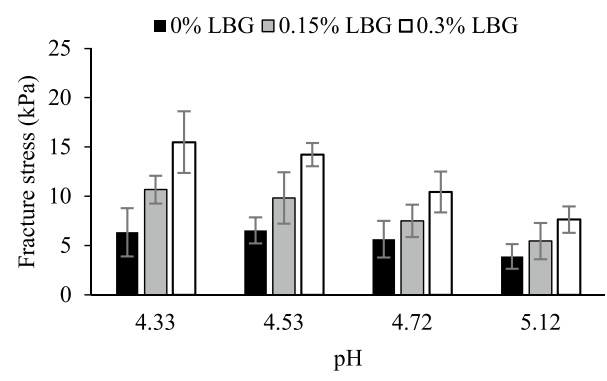

$58^{\circ} \mathrm{C}$

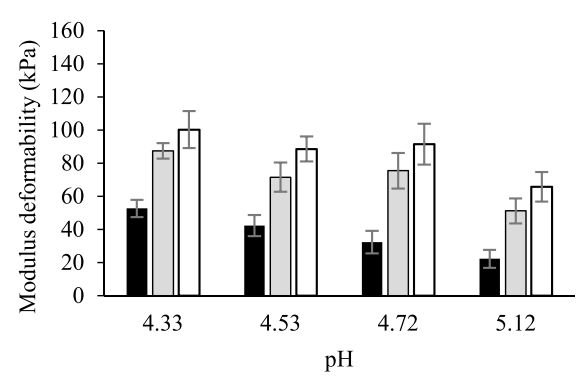

$78^{\circ} \mathrm{C}$
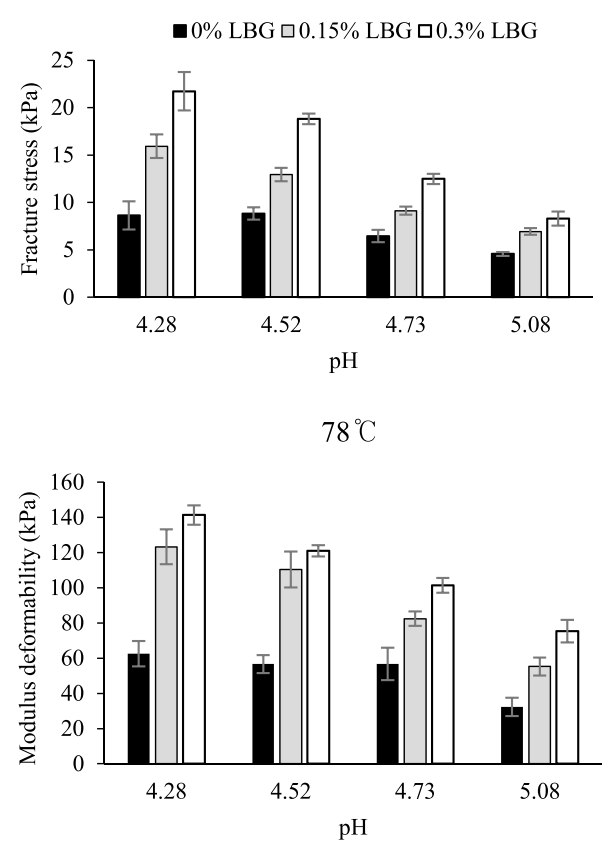
final network firmness. Secondly, increasing concentration of LBG was seen to contribute to firmer and stiffer textures.

Lastly, the 2 different coagulation temperatures were observed to impact on the material properties in the final product. Here, the cream cheese prepared via curd coagulation at $58^{\circ} \mathrm{C}$ was observed as having softer texture than the sample coagulated at a temperature of $78^{\circ} \mathrm{C}$. According to a previous study reported by Coutouly, Riaublanc, Axelos, and Gaucher [15], high heat treatment significantly increased the emulsion viscosity and affected the texture. Moreover, cream cheese with higher LBG content showed firmer and stiffer texture in all cream cheese trials. Multivariable linear regression analysis also showed temperature, $\mathrm{pH}$, and LBG content strongly influenced the textural attributes and Table 7 indicates that there are significant two-way interactions amongst each factor in texture. It clearly demonstrates that each processing step contributes to develop the texture, as well as interactions of textural attributes.

\section{Rheological Properties Analysis}

The small strain rheological properties $\left(G^{\prime}\right.$ and $\left.G^{\prime \prime}\right)$ of cream cheese made from different homogenised milks showed significant differences (Fig. 6). Both of $G^{\prime}$ and $G^{\prime \prime}$ of all the cream cheeses gradually increased over the range of frequency 0.1 to $10 \mathrm{~Hz}$ and higher values were measured in the cream cheese treated with higher homogenisation pressure (Fig. 6A). This demonstrates that homogenisation pressure had a significant effect on the viscoelastic characteristics in cream cheese which correlates well with the firmness measured by compression force. In addition, the elastic properties were more dominant, indicating a typical

Table 7 Multivariable linear regression analysis for the effects of $\mathrm{pH}$, LBG contents, and temperature as manufacturing variables on textural attributes

\begin{tabular}{lrcc}
\hline Factor & Coefficient & Standard error & $P$-value \\
\hline Firmness & & & \\
Temperature (A) & 1.16 & 0.21 & $<0.001$ \\
pH (B) & 11.26 & 3.13 & $<0.001$ \\
LBG (C) & 147.57 & 18.59 & $<0.001$ \\
A x B & -0.23 & 0.05 & $<0.001$ \\
B x C & -31.09 & 3.66 & $<0.001$ \\
A x C & 0.31 & 0.11 & $<0.05$ \\
Stiffness & & & \\
Temperature (A) & 7.61 & 1.36 & $<0.001$ \\
pH (B) & 57.52 & 20.33 & $<0.01$ \\
LBG (C) & 453.82 & 120.65 & $<0.001$ \\
A x B & -1.47 & 0.29 & $<0.001$ \\
B x C & -80.90 & 23.77 & $<0.001$ \\
A x C & 1.48 & 0.70 & $<0.05$ \\
\hline
\end{tabular}
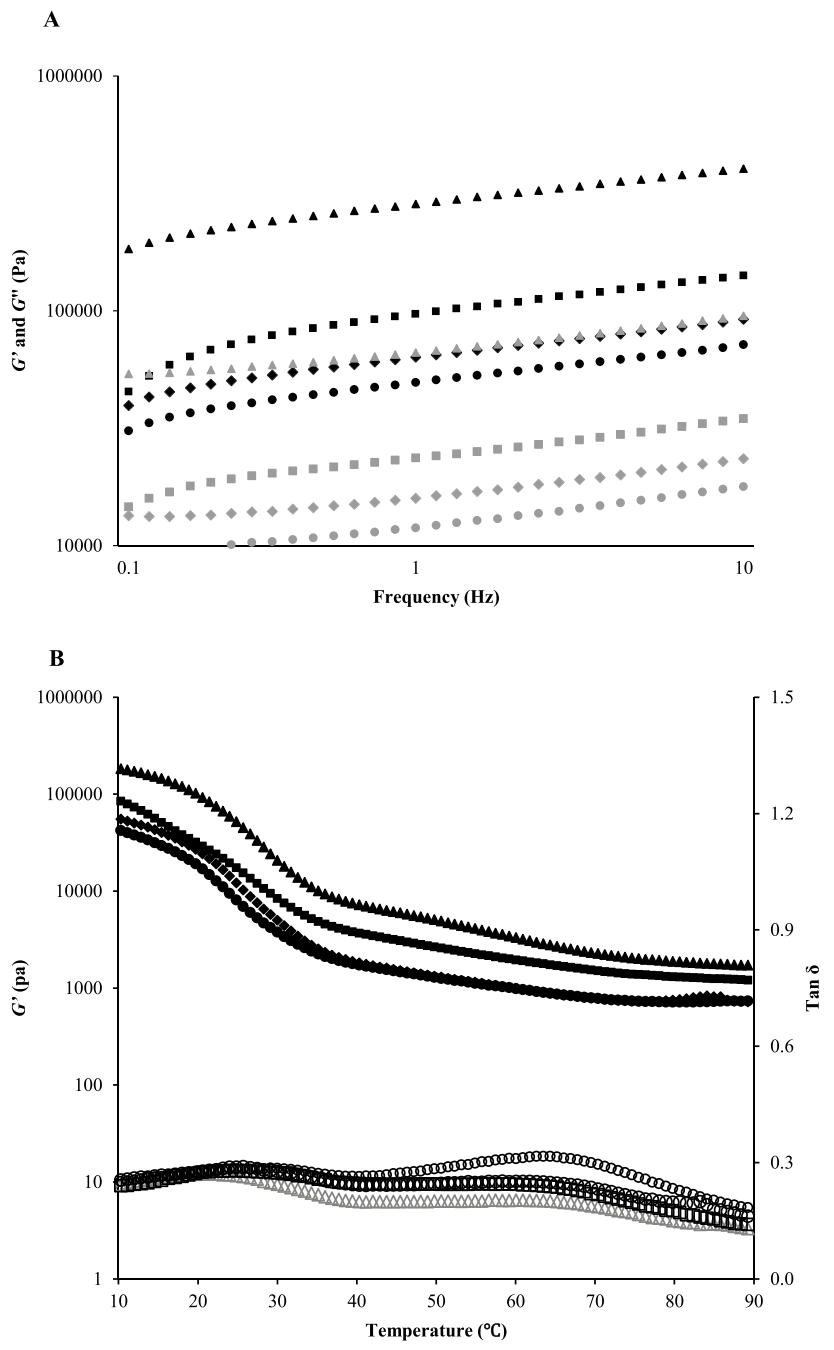

Fig. 6 Rheological properties of cream cheese made from cheese milk treated at different homogenisation pressures. A presents the result of frequency sweep test $\left(G^{\prime}-\mathbf{\Lambda}\right.$ : 180 bar, $\mathbf{\square}$ : 120 bar,

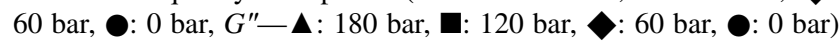
and $\mathrm{B}$ presents the result of temperature sweep test $\left(G^{\prime}-\mathbf{\Lambda}: 180 \mathrm{bar}\right.$, 口: 120 bar, $\diamond: 60$ bar, $0: 0$ bar, $\tan \delta$-: $\Delta 180$ bar, $\square: 120$ bar, $\diamond$ : 60 bar, : 0 bar)

gel-like characteristics, as it was clearly shown that $G^{\prime}$ was higher than $G^{\prime \prime}$ in all the samples. The $\tan \delta$ values $\left(G^{\prime \prime} / G^{\prime}\right.$, for which values $>1$ indicate a prevailing viscous component)) also confirmed that all the prepared cream cheese had elastic properties. These results are in agreement with previous studies which reported that the rheological properties of cream cheese were affected by increasing homogenisation pressure $[9,15]$. They reported that higher $G^{\prime}$ values in cream cheese treated at higher homogenisation pressure were observed through small amplitude oscillatory rheology tests.

In the results of the temperature sweep test, $G^{\prime}$ values of cream cheese subjected to pressures from 0 to $180 \mathrm{MPa}$ all decreased over the temperature range (Fig. 6B). The 
profiles of $G^{\prime}$ showed 2 different patterns before and after $40^{\circ} \mathrm{C}$. In the first stage of temperature $20 \sim 40^{\circ} \mathrm{C}$, the $G^{\prime}$ value steeply decreased and the second temperature section after $40^{\circ} \mathrm{C}$ showed steady decrease as temperature rose from $40^{\circ} \mathrm{C}$. The weakening rheological properties with the increasing temperature, $10 \sim 40^{\circ} \mathrm{C}$ is attributed to fat melting over this range. Above the melting point of milk fat, further decreases in modulus could be a consequence of the decreased strength of hydrogen bonds, due to contraction of casein molecules, and cause faster release of protein binding [12, 41].

Similar trends were observed in the commercial products such as full fat and Neufchatel cheeses with similar composition because more fat globules surrounded by protein melted dramatically below $40^{\circ} \mathrm{C}$, which affected the greater decrease of $G^{\prime}$ and $G^{\prime \prime}$ [9]. Interestingly, all samples demonstrated a peak for $\tan \delta$ at the temperature region of $20 \sim 30^{\circ} \mathrm{C}$ and a gradual decrease during the heating apart from the sample made at 0 bar. The values of tan $\delta$ below 0.3 in the test temperature range confirmed cream cheese had a predominantly elastic-like characteristics.
With the results of the particle size distribution and compression test, the smaller fat globules caused by higher homogenisation pressure, contributed to firmer texture by providing more opportunity for proteins to embed in the broadened interface.

The viscoelastic properties of cream cheese preparations made with formulation variables were also assessed through a frequency sweep. As presented in Table 8, the gel characteristics of all the cheese samples treated with different $\mathrm{pH}, \mathrm{LBG}$ and coagulation temperature had similar trends, showing an increase in $G^{\prime}$ as frequency increased and maintaining constant values of $G^{\prime}>G^{\prime \prime}$. Greater $G^{\prime}$ and $G^{\prime \prime}$ values were measured in cream cheese with higher amount of LBG and lower $\mathrm{pH}$. Regarding temperature, cream cheese treated at $78^{\circ} \mathrm{C}$ showed higher $G^{\prime}$ in all the treatment conditions and increasing frequency from 0.1 to $10 \mathrm{~Hz}$. A previous study reported that heat treatment $\left(\geq 80^{\circ} \mathrm{C}\right)$ produced acid milk gels with greater $G^{\prime}$ than the acid gels with no heat treatment. When the milk is heated $\left(\geq 69^{\circ} \mathrm{C}\right)$, denatured whey proteins associate with casein micelles in the serum as
Table 8 Comparison of storage modulus $\left(G^{\prime}\right)$ and loss modulus $\left(G^{\prime \prime}\right)$ in cream cheese preparations prepared with formulation variables

\begin{tabular}{|c|c|c|c|c|c|c|c|c|}
\hline \multicolumn{5}{|l|}{$58^{\circ} \mathrm{C}$} & \multicolumn{4}{|l|}{$78^{\circ} \mathrm{C}$} \\
\hline LBG & $\mathrm{pH}$ & $G^{\prime}$ at $0.1 \mathrm{~Hz}$ & $G^{\prime}$ at $1 \mathrm{~Hz}$ & $G^{\prime}$ at $10 \mathrm{~Hz}$ & $\mathrm{pH}$ & $G^{\prime}$ at $0.1 \mathrm{~Hz}$ & $G^{\prime}$ at $1 \mathrm{~Hz}$ & $G^{\prime}$ at $10 \mathrm{~Hz}$ \\
\hline \multirow[t]{4}{*}{$0.3 \%$} & 4.33 & 90,200 & 234,000 & 340,000 & 4.28 & 130,000 & 240,000 & 387,000 \\
\hline & 4.53 & 38,300 & 77,300 & 112,000 & 4.52 & 108,000 & 206,000 & 326,000 \\
\hline & 4.72 & 41,000 & 67,700 & 97,800 & 4.73 & 70,900 & 111,000 & 159,000 \\
\hline & 5.12 & 29,400 & 51,100 & 73,800 & 5.08 & 32,090 & 52,940 & 74,680 \\
\hline \multirow[t]{4}{*}{$0.15 \%$} & 4.33 & 49,900 & 79,600 & 116,000 & 4.28 & 55,600 & 91,100 & 136,000 \\
\hline & 4.53 & 23,200 & 40,500 & 59,400 & 4.52 & 47,400 & 82,800 & 122,000 \\
\hline & 4.72 & 18,000 & 29,600 & 43,000 & 4.73 & 27,200 & 38,400 & 51,800 \\
\hline & 5.12 & 14,700 & 24,300 & 38,300 & 5.08 & 19,700 & 25,300 & 41,200 \\
\hline \multirow[t]{4}{*}{$0 \%$} & 4.33 & 12,900 & 23,900 & 35,600 & 4.28 & 51,200 & 80,700 & 117,000 \\
\hline & 4.53 & 11,300 & 17,600 & 26,200 & 4.52 & 18,700 & 34,700 & 51,900 \\
\hline & 4.72 & 9680 & 14,000 & 20,800 & 4.73 & 18,040 & 23,900 & 29,700 \\
\hline & 5.12 & 8330 & 12,600 & 18,600 & 5.08 & 10,539 & 15,766 & 21,690 \\
\hline LBG & $\mathrm{pH}$ & $G^{\prime \prime}$ at $0.1 \mathrm{~Hz}$ & $G^{\prime \prime}$ at $1 \mathrm{~Hz}$ & $G^{\prime \prime}$ at $10 \mathrm{~Hz}$ & $\mathrm{pH}$ & $G^{\prime \prime}$ at $0.1 \mathrm{~Hz}$ & $G^{\prime \prime}$ at $1 \mathrm{~Hz}$ & $\begin{array}{l}G^{\prime \prime} \text { at } \\
10 \mathrm{~Hz}\end{array}$ \\
\hline \multirow[t]{4}{*}{$0.3 \%$} & 4.33 & 33,900 & 59,400 & 72,000 & 4.28 & 37,361 & 58,518 & 96,154 \\
\hline & 4.53 & 11,800 & 18,200 & 28,300 & 4.52 & 31,673 & 47,057 & 73,694 \\
\hline & 4.72 & 13,500 & 16,800 & 25,700 & 4.73 & 21,800 & 26,600 & 39,200 \\
\hline & 5.12 & 9810 & 13,000 & 18,400 & 5.08 & 10,654 & 16,887 & 28,790 \\
\hline \multirow[t]{4}{*}{$0.15 \%$} & 4.33 & 17,000 & 20,900 & 29,600 & 4.28 & 21,000 & 25,500 & 38,300 \\
\hline & 4.53 & 7080 & 9660 & 14,200 & 4.52 & 15,700 & 21,000 & 31,600 \\
\hline & 4.72 & 6870 & 8180 & 12,200 & 4.73 & 9994 & 12,872 & 16,358 \\
\hline & 5.12 & 5090 & 7370 & 12,500 & 5.08 & 5012 & 6688 & 12,076 \\
\hline \multirow[t]{4}{*}{$0 \%$} & 4.33 & 4860 & 6490 & 8650 & 4.28 & 16,100 & 20,700 & 31,300 \\
\hline & 4.53 & 3520 & 4340 & 6740 & 4.52 & 5910 & 9040 & 13,400 \\
\hline & 4.72 & 2840 & 3760 & 6170 & 4.73 & 6091 & 6178 & 8810 \\
\hline & 5.12 & 2510 & 2950 & 4470 & 5.08 & 3495 & 5604 & 5338 \\
\hline
\end{tabular}


Table 9 Multivariable linear regression analysis for the effects of $\mathrm{pH}$, LBG contents, and temperature as manufacturing variables on storage modulus

\begin{tabular}{llll}
\hline Factor & Coefficient & Standard error & $P$-value \\
\hline Storage modulus $\left(G^{\prime}\right)$ & & & \\
$\quad$ Temperature $(A)$ & 22,390 & 9,754 & $<0.05$ \\
pH (B) & 318,995 & 145,707 & $<0.05$ \\
LBG $($ C) & $3,467,303$ & 864,832 & $<0.001$ \\
A x B & $-4,874$ & 2,087 & $<0.05$ \\
B x C & $-834,032$ & 170,409 & $<0.001$ \\
A x C & 12,286 & 5,041 & $<0.05$ \\
\hline
\end{tabular}

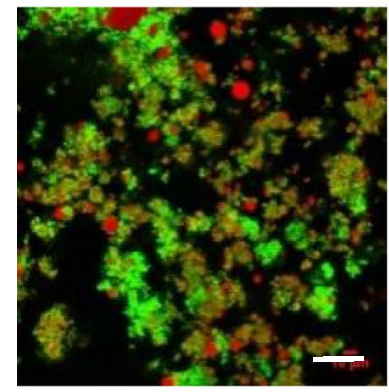

A

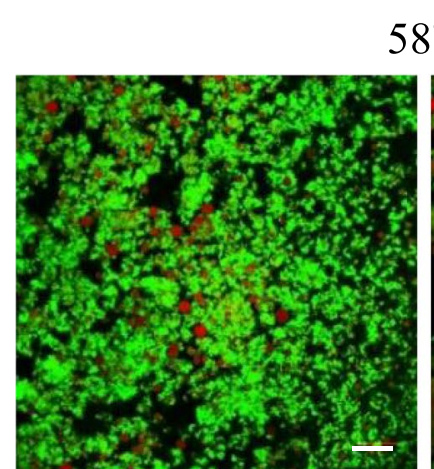

$\mathrm{pH} 4.33$

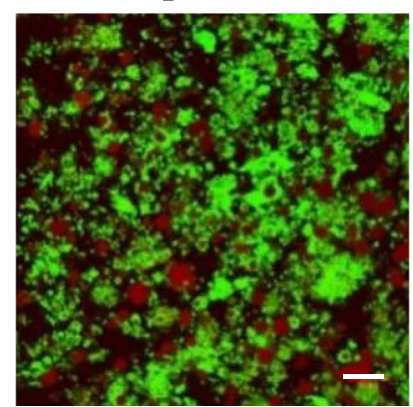

$\mathrm{pH} 4.72$

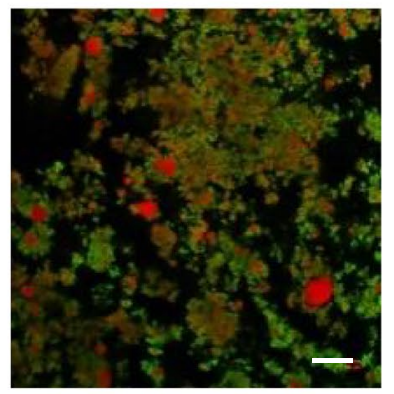

B

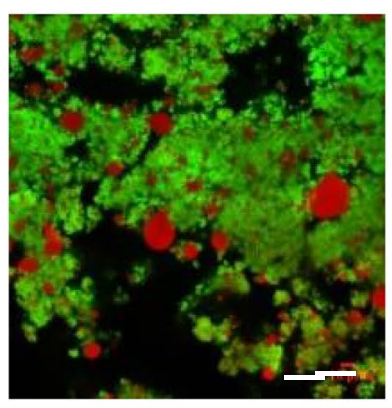

$\mathrm{C}$

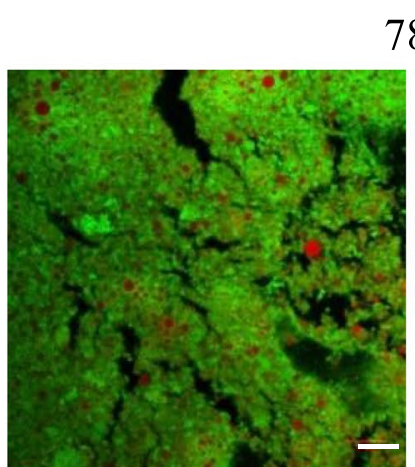

$\mathrm{pH} 4.28$

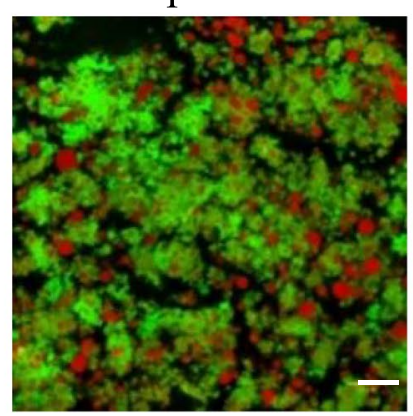

$\mathrm{pH} 4.73$

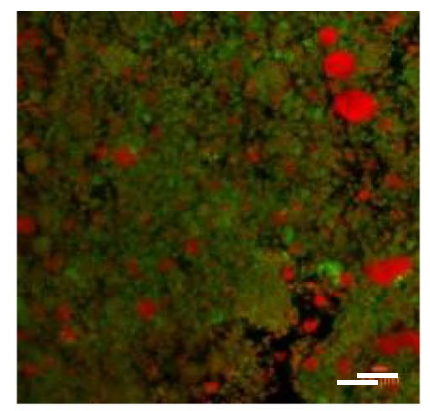

D

$78^{\circ} \mathrm{C}$

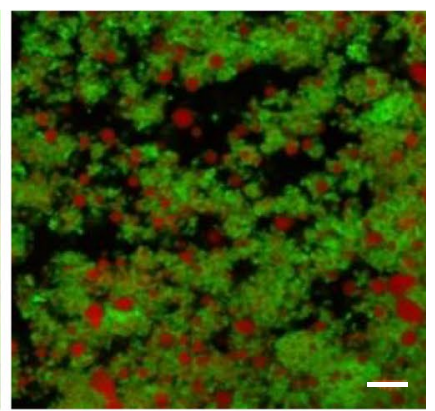

pH 4.52

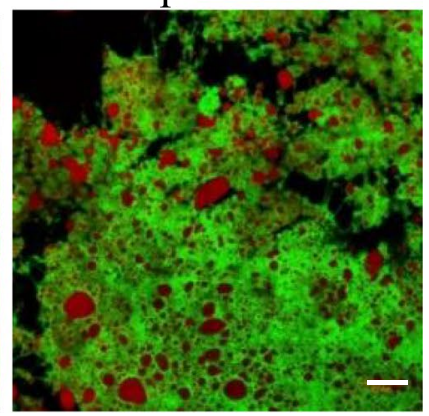

pH 5.08

Fig. 7 Typical confocal images staining with Nile red and Fast green by different homogenisation conditions (Above 4 images) A: 0 bar, B: 60 bar, C: 120 bar, and D: 180 bar. In images the fat, protein, and serum appear red, green, and black, respectively 
protein (green) interspersed with fat globules (red). The milk fat appears in two distinct states: smaller fat globules embedded in the protein matrix and larger pools of aggregated fat in the protein. It clearly shows differences in microstructure between cream cheese prepared from the cheese milk subjected to different homogenisation pressures. Denser microstructures with well-distributed protein and fat were observed when higher homogenisation pressures were applied to the cheese milk. A greater reduction in the particle size of the cream cheese, and disintegration of the casein micelle gel matrix as a result of the high pressure, led to an increase in a compact matrix with dense protein networks increasing the hardness and firmness [15]. However, the apparent higher incidence of free fat with increasing pressure should be equally noted. This observation goes somewhat counter to the particle size data of the corresponding samples and may be due to the size of free fat agglomerates exceeding the maximum size detection threshold measurable through dynamic light scattering and thus being excluded from measurement.

There were significant changes in the structure of cream cheese made from various formulations and the confocal method was used to visualise the changes. Figure 7 clearly shows differences in the microstructure of cream cheese prepared at different $\mathrm{pH}$ and coagulation temperatures. For cream cheese at lower $\mathrm{pH}$, a denser structure was observed. On the other hand, cream cheese with a high $\mathrm{pH}$ over 5.0 showed swollen particle form. Monteiro, Tavares, Kindstedt, and Gigante [40] outlined that there might be protein to water interactions which induce the swelling of the casein network, as well as softer texture in the structure of cream cheese exposed to volatile ammonia to increase the $\mathrm{pH}$ to about 5.3. Cream cheese coagulated at $58^{\circ} \mathrm{C}$ showed a small aggregation form, with small particle containing proteins; whereas higher heat treatment, $78^{\circ} \mathrm{C}$, appeared to result in a rougher structure with more crack zone-containing whey, compared with the image of cream cheese made at lower heat treatment. In addition, the aggregated form at $78^{\circ} \mathrm{C}$ showed a denser structure, contributing to the firmer and stiffer texture. LBG content did not appear to significantly modify the structure in cream cheese prepared with different LBG levels (image not shown).

\section{Conclusions}

We have determined that the structural, material, and functional properties of analogue cream cheeses prepared using GDL as acidulant can be predictably controlled through key processing variables within the manufacturing process, either in isolation or in combination. In terms of controllable processing variables, increasing homogenisation pressure of cheese milks resulted in smaller fat globules, which in turn provided increasing reinforcement to the curd structure with a resulting firmer texture to the lab scale cream cheese. The increasing surface area of protein-coated fat droplets allow for more extensive interaction between droplets and the protein network. The increase in curd strength during acidification translates to the properties of the final microgel structure formed during the subsequent heating/mixing/cooling process. A relationship between structure and material properties was also seen to extend to the physical properties of the final cheeses, as observed by variations in the volume of released serum.

In addition, other processing elements including the incremental lowering of $\mathrm{pH}$ towards the isoelectric point, addition of LBG, and increasing coagulation temperature conditions were also observed to be significant factors which were able to manipulate structural behaviours towards final materials with increased firmness. Reciprocal interactions between them were confirmed by multivariable linear regression. In this way, individual or combinations of processing effects could be applied towards specific material property requirements, allowing for products to be produced on a relative scale of softness to firmness. This approach provides practical information for developing new cream cheese products with targeted functionality to meet different demands or applications.

Confocal images showing the changes in structure of cream cheese with $0.3 \%$ LBG by different $\mathrm{pH}$ and coagulation temperature. The scale bar indicates $25 \mu \mathrm{m}$.

Acknowledgements One of the authors, J. Kim, acknowledges Fonterra Cooperative Group Ltd for financial support for his $\mathrm{PhD}$ fellowship. All the authors wish to thank the researchers of Fonterra Research and Development Centre, including Siew Kim Lee (and experimental help from Manon Lepine) for the original ideas and most of the technical detail in the model cheesemaking methodologies and its visiting research fellow, Prof. A. Foegeding, for technical assistance and valuable discussion input.

Funding Open Access funding enabled and organized by CAUL and its Member Institutions.

\section{Declarations}

Conflict of Interest This study was funded by the Fonterra Cooperative Group Ltd. Mr J. Kim, acknowledges Fonterra Cooperative Group Ltd for financial support for his Ph.D. fellowship. Dr P. Watkinson acknowledges employment with the Fonterra Cooperative Group Ltd. Prof. M. Golding acknowledges the Fonterra Cooperative Group Ltd for provision of funding support in role of Chair of Food Structure at Massey University.

Open Access This article is licensed under a Creative Commons Attribution 4.0 International License, which permits use, sharing, adaptation, distribution and reproduction in any medium or format, as long as you give appropriate credit to the original author(s) and the source, provide a link to the Creative Commons licence, and indicate if changes were made. The images or other third party material in this article are included in the article's Creative Commons licence, unless indicated otherwise in a credit line to the material. If material is not included in the article's Creative Commons licence and your intended use is not permitted by statutory regulation or exceeds the permitted use, you will 
need to obtain permission directly from the copyright holder. To view a copy of this licence, visit http://creativecommons.org/licenses/by/4.0/.

\section{References}

1. United States Department of Agriculture (USDA), in USDA Specifications for cream cheese, cream cheese with other foods, and related products. (Dairy Division, Washington, 1994). p. 1-5

2. USDA, in Dairy Products. (National Agricultural Statistics Service, Washington, 2019). p. 3

3. P.F. Fox, T.P. Guinee, T.M. Cogan, P.L.H. McSweeney, Fundamentals of Cheese Science, 2nd edn. (Aspen Publ, Gaithersburg, 2000), pp. 543-588

4. C. Phadungath, J. Sci. Technol. 27(1), 191-199 (2005)

5. T.P. Guinee, P.D. Pudja, N.Y. Farkye, Cheese: Chemistry, Physics and Microbiology, 2nd edn. (Chapman \& Hall, London, 1993), pp. 363-419

6. A. Bot, F.A.M. Kleinherenbrink, M. Mellema, C.K. Magnani, in Handbook of Food Products Manufacturing. ed. by Y.H. Hui (John Wiley \& Sons Inc., New Jersey, 2007), pp. 651-672

7. C. Sanchez, J.L. Beauregard, M.H. Chassagne, J.J. Bimbenet, J. Hardy, J. Food Eng. 23, 579-594 (1994)

8. C. Sanchez, J.L. Beauregard, M.H. Chassagne, J.J. Bimbenet, J. Hardy, J. Food Eng. 23, 595-608 (1994)

9. M. Brighenti, L.S. Govindasamy, J.J. Jaeggi, M.E. Johnson, J.A. Lucey, J. Dairy Sci. 101(8), 6762-6775 (2018)

10. C. Lopez, Curr. Opin. Colloid Interface Sci. 16(5), 391-404 (2011)

11. M.G. Hayes, A.L. Kelly, J. Dairy Res. 70, 297-305 (2003)

12. J.A. Lucey, M.E. Johnson, D.S. Horne, J. Dairy Sci. 86(9), 2725$2743(2003)$

13. P. Schenkel, R. Samudrala, J. Hinrichs, Int. Dairy J. 30(2), 79-87 (2013)

14. M.A. Rudan, D.M., Barbano, M.R. Gu, P.S. Kindstedt, J Dairy Sci. 81(8), 2065-2076 (1998)

15. A. Coutouly, A. Riaublanc, M. Axelos, I. Gaucher, Dairy Sci. \& Technol. 94, 125-144 (2014)

16. M. Rowney, M.W. Hickey, P. Roupas, D.W. Everett, J. Dairy Sci. 86, 712-718 (2003)

17. M. Brighenti, L.S. Govindasamy, K. Lim, K. Nelson, J.A. Lucey, J. Dairy Sci. 91(812), 4501-4517 (2008)

18. Y.L. Xiong, J.M. Aguilera, J.E. Kinsella, J. Food Sci. 56, 920-925

19. P. Walstra, T.J. Geurts, A. Noomen, A.A. Jellema, M.A.J.S. van Boekel, Dairy technology: Principles of milk properties and principles (Marcel Dekker, New York, 1999)

20. D.W. Ningtyas, B. Bhandari, N. Bansal, S. Prakash, Int. J. Dairy Technol. 71(2), 417-431 (2018)
21. T. Truong, M. Palmer, N. Bansal, B. Bhandari, Effect of milk fat globule size on the physical functionality of dairy products (Springer, Cham, 2016), pp. 53-56

22. D.S. Horne, Casein micelle structure and stability, 2nd edn. (Academic Press, London, 2014), pp. 169-200

23. J.A. Lucey, M. Tamehana, H. Singh, P.A. Munro, Food Res. Int. 31, 147-155 (1998)

24. P.F. Fox, T.P. O'Connor, P.L.H. McSweeney, T.P. Guinee, N.M. O’Brien, Adv. Food Nutr. Res. 39, 163-328 (1996)

25. S.P.F.M. Roefs, P. Walstra, D.G. Dalgleish, D.S. Horne, Neth. Milk Dairy J. 39, 119-122 (1985)

26. D.W. Everett, M.A.E. Auty, Int. Dairy J. 18, 759-773 (2008)

27. D.S. Horne, Food colloids and Polymers: Stability and Mechanical Properties (Royal Society of Chemistry, Cambridge, 1993), pp. $260-265$

28. J.A. Lucey, C.T. Teo, P.A. Munro, H. Singh, H. J. Dairy Res. 64, 591-600 (1997)

29. P. Watkinson, G. Boston, O.H. Campanella, C. Coker, K.A. Johnston, M. Luckman, N.J. White, N. Le, Lait 77, 109-120 (1997)

30. AOAC, Official method of Analysis, 18th edn. (Washington DC, Association of Officiating Analytical Chemists, 2005)

31. M.C. Michalski, V. Briard, F. Michel, Lait 81(6), 787-796 (2001)

32. P.N. Kocher, E.A. Foegeding, J. Food Sci. 58(5), 1040-1046 (1993)

33. A.F. Wolfschoon-Pombo, B.P. Dang, B.C. Chiriboga, Int. Dairy J. 85, 129-136 (2018)

34. M. Rosenberg, Z. Wang, S.L. Chuang, C.F. Shoemaker, J. Food Sci. 60(3), 640-644 (1995)

35. V. Raikos, Food Hydrocolloids 24, 59-265 (2010)

36. H.E. Batal, A. Hasib, A. Ouatmane, A. Jaouad, M. Mohammed, Naïm, M. Revue de génie industriel. 8, 55-62 (2012)

37. M. Almena-Aliste, P.S. Kindstedt, Aust. J. Dairy Technol. 60, 225-230 (2005)

38. P. Sfakianakis, C. Tzia, Foods. 3(1), 176-193 (2014)

39. C. Sanchez, J.L. Beauregard, M. Bride, W. Buchheim, J. Hardy, Nahrung 40, 108-116 (1996)

40. R.R. Monteiro, D.Q. Tavares, P.S. Kindstedt, M.L. Gigante, J. Food Chem. 74(2), 112-117 (2009)

41. C.M. Bryant, D.J. McClements, Trends Food Sci. Technol. 9 , 143-151 (1998)

42. J.A. Lucey, C.T. Teo, P.A. Munro, H. Singh, J. Dairy Res. 64, 591-600 (1997)

Publisher's Note Springer Nature remains neutral with regard to jurisdictional claims in published maps and institutional affiliations. 